\title{
Ideal intraarticular application dose of tranexamic acid in primary total knee arthroplasty: a prospective, randomized and controlled study
}

\author{
Jun Wu ${ }^{1,2 \#}$, Yi-Qin Zhou ${ }^{1 \#}$, Jian-Hua Deng ${ }^{2}$, Ya-Guang Han ${ }^{1}$, Yu-Chang Zhu ${ }^{2,3}$, Qi-Rong Qian ${ }^{1}$ \\ ${ }^{1}$ Department of Joint Surgery and Sports Medicine, Shanghai Changzheng Hospital, Naval Medical University, Shanghai, China; ${ }^{2}$ Department of \\ Orthopaedic Surgery, Nantong Sixth People's Hospital, Nantong, China; ${ }^{3}$ Department of Orthopaedic Surgery, Shanghai Tenth People's Hospital, \\ Tongji University, Shanghai, China \\ Contributions: (I) Conception and design: J Wu, YC Zhu, QR Qian; (II) Administrative support: QR Qian; (III) Provision of study materials or \\ patients: JH Deng, YC Zhu, QR Qian; (IV) Collection and assembly of data: J Wu, YQ Zhou, YG Han; (V) Data analysis and interpretation: J Wu, \\ YQ Zhou; (VI) Manuscript writing: All authors; (VII) Final approval of manuscript: All authors. \\ \#These authors contributed equally to this work. \\ Correspondence to: Qi-Rong Qian. 415\#, Fengyang Road, Huangpu District, Shanghai 200003, China. Email: qianqr@163.com; Yu-Chang Zhu. 301\#, \\ Middle Yanchang Road, Jing'an District, Shanghai 200072, China. Email: drzhuyc@126.com.
}

Background: Combined use of tranexamic acid (TXA) via intravenous (IV) and intraarticular (IA) routes is more effective in reducing blood loss than any single route in primary total knee arthroplasty (TKA), but the optimal dose of topical administration remains controversial. The aim of this study was to evaluate the efficacy and safety of different combined administration strategies and to determine an ideal IA application dose of TXA.

Methods: A total of 180 patients who underwent primary TKA were randomized to four groups (groups $\mathrm{A} / \mathrm{B} / \mathrm{C} / \mathrm{D})$ with the same single $\mathrm{IV}$ dose of $1 \mathrm{~g}$ TXA preoperatively and four different IA doses after wound closure: group A (0 g), group B (1 g), group C (2 g), and group D (4 g). The primary outcome measures included wound blood drainage, hemoglobin $(\mathrm{Hb})$ concentration, and blood transfusion. The secondary outcome measures included wound complications, deep vein thrombosis (DVT) and symptomatic pulmonary embolism (PE).

Results: A total of 165 patients finished at least 3 months of follow-up visits. The amount of 48-hour blood drainage and calculated total blood loss in four groups decreased with the increased dose of TXA injected via IA route, and no difference was observed between groups $\mathrm{C}$ and $\mathrm{D}(\mathrm{P}=0.6237$ and $\mathrm{P}=0.9923$, respectively). $\mathrm{Hb}$ was significantly higher in groups $\mathrm{C}$ and $\mathrm{D}$ than in groups $\mathrm{A}$ and $\mathrm{B}$ at postoperative day 1,3 and 7 , respectively $(\mathrm{P}<0.0001)$. Hb in group A was significantly lower than that in groups $\mathrm{C}$ and $\mathrm{D}$ at 1 month after surgery, whereas no intergroup difference was found in other groups. No intergroup difference was observed regarding DVT, PE or wound complications.

Conclusions: The topical injection of $2 \mathrm{~g}$ TXA may have reached the "ceiling effect" of local use. A preoperative IV dose of $1 \mathrm{~g}$ TXA combined with an IA dose of $2 \mathrm{~g}$ TXA could be an optimal combination regimen.

Keywords: Tranexamic acid (TXA); total knee arthroplasty (TKA); intra-articular injection; topical use

Submitted Apr 01, 2020. Accepted for publication Sep 25, 2020.

doi: 10.21037/atm-20-3064

View this article at: http://dx.doi.org/10.21037/atm-20-3064 


\section{Introduction}

Total knee arthroplasty (TKA) is a well-accepted surgical treatment with reliable results for knee joint diseases. With increases in life expectancy and improvements in medical care, an increasing number of patients will receive TKA (1). During the past decade, tremendous efforts have been made to achieve quick recovery in functional performance after TKA. Such efforts based on a multimodal "fast track" methodology focus on pain relief, early mobilization, and reduced blood loss, leading to a reduction in the length of hospital stay as well as early recovery of knee function (2). Nonetheless, intraoperative and postoperative bleeding remains an essential issue in TKA, causing swelling, pain, anemia and anxiety, followed by prolonged hospital stays, increased medical costs, and impaired early postoperative recovery. It has been reported that patients can lose as much as $1,450 \mathrm{~mL}$ of blood during TKA without intervention, and that approximately $10 \%$ of patients require blood transfusions due to symptomatic anemia, which can be fatal to elderly patients with cardiopulmonary insufficiency (3). Therefore, approaches to effectively reduce blood loss during the perioperative period are of continuing interest.

The use of tranexamic acid (TXA) in total knee and hip arthroplasty has been well established in recent years. In TKA, both the intravenous (IV) and intraarticular (IA) (or topical) administration of TXA have been shown to effectively reduce blood loss after surgery. A number of meta-analyses and prospective clinical studies have shown that a combined IV and IA regimen of TXA seems to be one of the most effective methods to reducing postoperative blood loss, without severe thromboembolic complications (4-8), and usually, the IV administration of TXA in clinical practice is set to $10-20 \mathrm{mg} / \mathrm{kg}$ according to the instruction manual. Nevertheless, the indications and dose for its local use are not clear.

Most of the time, the topical dose is based on clinical experience and recommendations from the so-called "Orthopedic Experts' Consensus", and the optimal dose and safety of intra-articular administration remain controversial. In our previous study (9), different combined administration strategies of TXA were investigated, and the preliminary results confirmed that the amount of blood loss decreased with the increase in the dose of TXA administered via IA injection. However, we did not find a meaningful difference in the hemostatic effect between IA injections of 2 and $3 \mathrm{~g}$, which may be due to the "ceiling effect" or the gentle gradient between the experimental groups. Thus, based on the pilot study, this prospective, randomized and controlled study was conducted to further investigate the effect and safety of single IV administration and different combined administration regimens of TXA in primary TKA and to determine the optimal IA dose with relatively good titers. We present the following article in accordance with the CONSORT reporting checklist (available at http://dx.doi. org/10.21037/atm-20-3064).

\section{Methods}

\section{Study design}

This prospective, randomized, controlled study was registered in the Chinese Clinical Trial Registry (ChiCTRTRC-1800018751). The study was conducted in accordance with the Declaration of Helsinki (as revised in 2013). Approval was obtained from the Ethics Committee of Nantong Sixth People's Hospital (Approval No. 201704), and written informed consent was obtained from all participants.

\section{Inclusion and exclusion criteria}

The inclusion criteria were as follows: (I) patients with unilateral degenerative osteoarthritis of the knee according to diagnostic criteria for knee osteoarthritis (ICD-10 M17.901); (II) normal preoperative hemoglobin (Hb) levels $(120 \mathrm{~g} / \mathrm{L} \leq \mathrm{Hb} \leq 160 \mathrm{~g} / \mathrm{L}$ in males and $110 \mathrm{~g} / \mathrm{L} \leq \mathrm{Hb}$ $\leq 150 \mathrm{~g} / \mathrm{L}$ in females), normal coagulation function and renal function; (III) normal deep veins in the legs on color Doppler echography; and (IV) stable concurrent chronic diseases, if any.

The exclusion criteria were as follows: (I) patients with anemia $(\mathrm{Hb}<120 \mathrm{~g} / \mathrm{L}$ in males and $\mathrm{Hb}<110 \mathrm{~g} / \mathrm{L}$ in females); (II) patients with abnormal coagulation function; (III) patients with liver or kidney dysfunction (patients with any abnormality in major items of liver and renal hematological examinations or abnormal preoperative urinalysis); (IV) patients with a history of bleeding disorders; (V) patients with a history of deep vein thrombosis (DVT); (VI) patients with hypercoagulability or risk factors for thrombosis (e.g., atrial fibrillation, coronary stenting, tumors, or long-term use of hormones); and (VII) patients with a known history of TXA hypersensitivity.

\section{Sample size calculation}

A prior calculation was conducted to determine the sample 


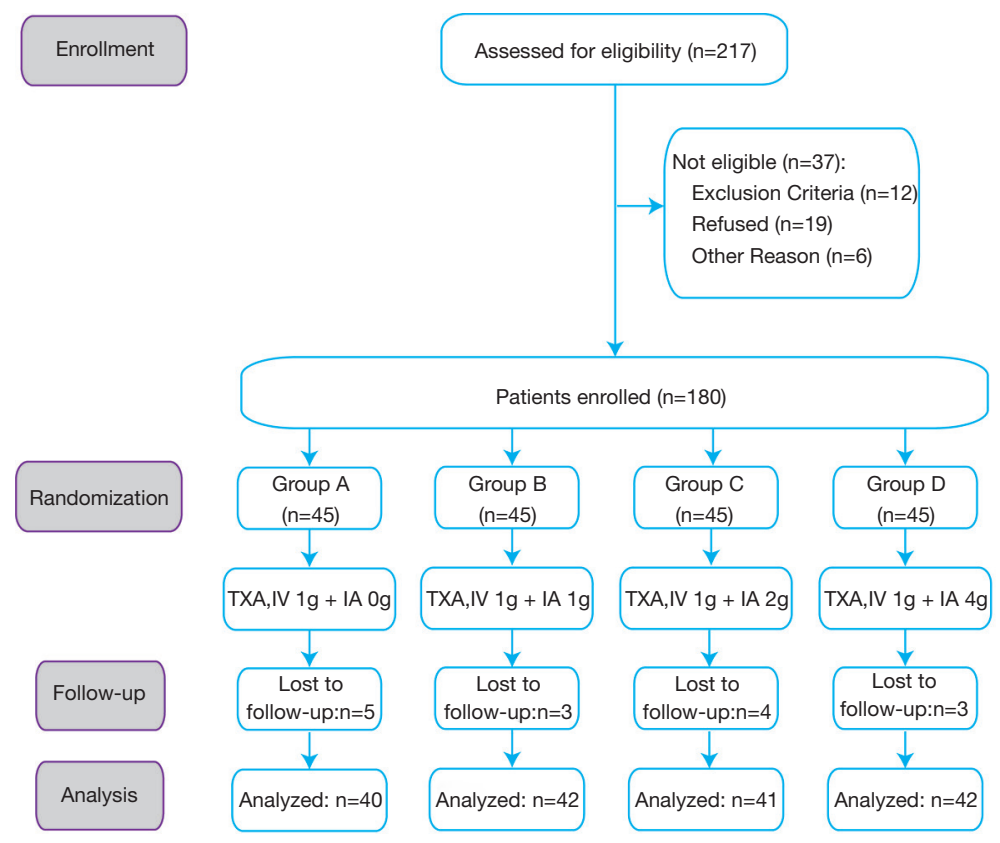

Figure 1 CONSORT flow diagram of patients eligible for this study. CONSORT, Consolidated Standards of Reporting Trials; TXA, tranexamic acid; IV, intravenous; IA, intraarticular.

size with $80 \%$ power at a $5 \%$ significant level. A blood loss of $400 \mathrm{~mL}$ is generally considered clinically significant. In patients with a mean $\mathrm{Hb}$ concentration of $130 \mathrm{~g} / \mathrm{L}, 400 \mathrm{~mL}$ blood would contain $52 \mathrm{~g} \mathrm{Hb}$, equal to the $\mathrm{Hb}$ content of one unit of red cell. Total blood loss during TKA was approximately $1,500 \mathrm{~mL}$ without intervention, as previously described (3). To obtain statistical power, 31 patients were required in each group and the recruitment goal was determined to be 180 patients as anticipating a drop-out rate of approximately $20 \%$.

\section{Patient and trial intervention}

From August 2017 to February 2019, a total of 180 patients who met the inclusion criteria indicated above were enrolled in this study. A total of 109 patients underwent left TKA, and 71 patients underwent right TKA. The enrolled patients were randomly allocated into four groups by Microsoft Excel software, version 2016 (Microsoft Corporation, Redmond, WA, USA): groups A, B, C and $\mathrm{D}$, with 45 patients each. The same single dose of TXA was administered through IV injection 30 minutes before tourniquet inflation, and different doses of TXA were administered through IA injection via the drainage tube after wound closure: group A ( $1 \mathrm{~g}$ IV + saline with no TXA), group B (1 g IV + $1 \mathrm{~g}$ IA), group C (1 g IV + $2 \mathrm{~g} \mathrm{IA})$, and group D (1 g IV + $4 \mathrm{~g}$ IA). (Figure 1).

Sex, age, body mass index (BMI), severity of osteoarthritis (Kellgren-Lawrence Classification of Osteoarthritis), preoperative $\mathrm{Hb}$ concentration, platelet (PLT) count, preoperative prothrombin time $(\mathrm{PT})$ and activated partial thromboplastin time (APTT) were recorded.

\section{Surgical procedure and perioperative management}

General anesthesia was adopted. Second-generation cephalosporin antibiotics were used for prophylaxis of infection 30 minutes before the start of surgery. The standard medial parapatellar approach and posterior stabilized cemented prosthesis (NexGen ${ }^{\circledR}$ LPS; Zimmer Biomet, Warsaw, IN, USA) without patellar resurfacing was applied for TKA. One gram of TXA was administered intravenously thirty minutes before tourniquet inflation in all four groups. After the surgical incision was closed, $50 \mathrm{~mL}$ of TXA-saline solution (TXA: group A: $0 \mathrm{~g}$; group B: $1 \mathrm{~g}$; group C: $2 \mathrm{~g}$; group D: $4 \mathrm{~g}$ ) was injected into the joint cavity via the drainage tube. The drainage tube was clamped for 1 hour before suction.

Postoperative management was based on the "Experts' consensus in enhanced recovery after total hip and knee 
arthroplasty in China: perioperative management" (10). The drainage tube was removed 48 hours after surgery.

All procedures were performed by the same senior surgeon experienced in TKA. The patients, surgeons, ward nurses, and researchers were blinded to the patient grouping. The nurses who administered TXA during surgery did not participate in postoperative care, follow-up visits or data analysis.

\section{Prophylaxis of deep vein thromboembolism (DVT)}

A combination of physical and chemical prophylaxis of DVT was administered according to standard practice $(11,12)$. All patients received lower-extremity muscle strength training preoperatively and started passive and active physical therapy after anesthesia resolution. A lowerextremity inflatable venous pump was applied on the first postoperative three days. All patients were encouraged to walk as far as possible in the inpatient ward. Low-molecularweight heparin (4000 Axa IU, Clexane, sodium injection) was first administered 12 hours after surgery and then every 24-hour until discharge. An additional $10 \mathrm{mg} /$ day of Rivaroxaban was prescribed for 3 weeks after hospital discharge.

\section{Blood transfusion protocol}

The perioperative blood transfusion protocol was standardized according to the guidelines provided by the National Health Commission of the People's Republic of China. According to this protocol, a blood transfusion was indicated when the $\mathrm{Hb}$ concentration was $<70 \mathrm{~g} / \mathrm{L}$ or when a patient developed any anemia-related organ dysfunction, such as an alteration in mental status or palpitation (regardless of the $\mathrm{Hb}$ concentration), especially in elderly patients with poor heart and lung function.

\section{Outcome measures}

The primary outcome measures were postoperative blood drainage, $\mathrm{Hb}$ concentration, and units of blood transfusion. Routine blood tests were performed at 1, 3, 7 and 30 days after surgery. Total blood loss was calculated according to the Good's formula (13):

$$
\mathrm{Hb}_{\text {loss }}=\mathrm{BV} \times\left(\mathrm{Hb}_{\mathrm{i}}-\mathrm{Hb}_{\mathrm{e}}\right) \times 0.001+\mathrm{Hb}_{\mathrm{t}}
$$

where $\mathrm{Hb}_{\text {loss }}(\mathrm{g})$ is the amount of $\mathrm{Hb}$ lost, $\mathrm{BV}$ is the blood volume $(\mathrm{mL}), \mathrm{Hb}_{\mathrm{i}}(\mathrm{g} / \mathrm{L})$ is the $\mathrm{Hb}$ concentration before surgery, $\mathrm{Hb}_{\mathrm{e}}(\mathrm{g} / \mathrm{L})$ is the $\mathrm{Hb}$ concentration on the 5 th day after surgery and $\mathrm{Hb}_{\mathrm{t}}(\mathrm{g})$ is the total amount of allogeneic $\mathrm{Hb}$ transfused. One unit of banked red blood cell was considered to contain $50 \mathrm{~g} \mathrm{Hb}$ according to measurement at our hospital blood center. In this study, Hb value on the 7th day after surgery was used to replace that on the 5 th day in the Good's formula. The blood loss (ml) was related to the patient's preoperative $\mathrm{Hb}$ value $(\mathrm{g} / \mathrm{L})$ :

Blood loss $=1000 \times \mathrm{Hb}_{\text {loss }} / \mathrm{Hb}_{\mathrm{i}}$

$\mathrm{BV}$ was estimated according to the method of Nadler and colleagues (14), taking body height, weight, and sex into account:

$$
\mathrm{BV}=\mathrm{K} 1 \times \text { height }(\mathrm{m})^{3}+\mathrm{K} 2 \times \text { weight }(\mathrm{kg})+\mathrm{K} 3
$$

In males, $\mathrm{K} 1=0.3669, \mathrm{~K} 2=0.03219, \mathrm{~K} 3=0.6041$; in females, $\mathrm{K} 1=0.3561, \mathrm{~K} 2=0.03308, \mathrm{~K} 3=0.183333$. The secondary outcome measures were the incidence of thromboembolic events, including DVT and pulmonary embolism (PE). Doppler echography was performed to screen for DVT in the lower legs at 1 week, 1 month, and 3 months after surgery, and symptomatic PE was recorded. At each follow-up visit, the KSS scale was used to assess the patients' knee joints for pain, stability, and function.

\section{Data analysis}

The statistical analysis was performed using Prism software, version 8.0.2 (GraphPad Software Inc., San Diego, CA, USA). Prior to data analysis, potential confounders (demographic data, preoperative laboratory values and severity of osteoarthritis) among the study groups as well as primary and secondary outcomes were evaluated for distribution with summary statistics, including the mean and standard deviation for normally distributed quantitative data and percentage for qualitative data. Binomial data are presented as the number and percentage. One-way analysis of variance (One-way ANOVA) was used for comparisons of continuous variables between groups. Non-normally distributed quantitative data were compared using ranksum tests. The chi-square test was applied to compare differences in categorical data between groups. $\mathrm{P}<0.05$ was considered statistically significant.

\section{Results}

The postoperative follow-up visit was scheduled for the four groups of patients on a regular basis. A total of 40, 42, 41 , and 42 patients in groups A, B, C, and D, respectively, received at least 3 months of follow-up. Fifteen patients did not complete the full duration of follow-up because of 
Table 1 Comparison of baseline data among 4 groups

\begin{tabular}{|c|c|c|c|c|c|}
\hline Baseline data & $\begin{array}{c}\text { Group A } \\
(\text { IV } 1 \mathrm{~g}+\text { IA } 0 \mathrm{~g})\end{array}$ & $\begin{array}{c}\text { Group B } \\
(\text { IV } 1 \mathrm{~g}+\mathrm{IA} 1 \mathrm{~g})\end{array}$ & $\begin{array}{c}\text { Group C } \\
(\text { IV } 1 \mathrm{~g}+\text { IA } 2 \text { g) }\end{array}$ & $\begin{array}{c}\text { Group D } \\
(\text { IV } 1 \mathrm{~g}+\text { IA } 4 \mathrm{~g})\end{array}$ & $P$ value \\
\hline Sex (male/female) & $17 / 28$ & $17 / 28$ & $18 / 27$ & $21 / 24$ & 0.8035 \\
\hline Body weight (kg) & $66.0 \pm 6.7$ & $66.0 \pm 6.7$ & $66.5 \pm 7.0$ & $66.7 \pm 5.8$ & 0.9408 \\
\hline BMI $\left(\mathrm{kg} / \mathrm{m}^{2}\right)$ & $24.4 \pm 2.9$ & $23.9 \pm 2.8$ & $24.1 \pm 2.9$ & $23.6 \pm 2.5$ & 0.5777 \\
\hline PT (s) & $11.9 \pm 0.5$ & $12.1 \pm 0.6$ & $12.0 \pm 0.7$ & $11.9 \pm 0.6$ & 0.3383 \\
\hline APTT (s) & $29.9 \pm 4.0$ & $30.7 \pm 3.1$ & $30.7 \pm 3.0$ & $31.0 \pm 3.0$ & 0.4332 \\
\hline $\operatorname{PLT}\left(\times 10^{9} / \mathrm{L}\right)$ & $220 \pm 23$ & $216 \pm 63$ & $233 \pm 64$ & $218 \pm 60$ & 0.4580 \\
\hline
\end{tabular}

BMI, body mass index; ASA, American Society of Anesthesiology; Hb, hemoglobin; Pre-o., preoperative; BMI, body mass index; Kellgren-Lawrence, The Kellgren-Lawrence Classification grading system of osteoarthritis; PT, prothrombin time; APTT, activated partial thromboplastin time; PLT, platelets count; ASA, American Society of Anesthesiology; Pre-o., preoperative; Hb, hemoglobin.

Table 2 Comparison of postoperative outcomes among 4 groups

\begin{tabular}{|c|c|c|c|c|c|}
\hline Postoperative outcome & $\begin{array}{c}\text { Group A } \\
\text { (IV } 1 \mathrm{~g}+\text { IA } 0 \mathrm{~g})\end{array}$ & $\begin{array}{c}\text { Group B } \\
(\text { IV } 1 \mathrm{~g}+\text { IA } 1 \mathrm{~g})\end{array}$ & $\begin{array}{c}\text { Group C } \\
\text { (IV } 1 \mathrm{~g}+\text { IA } 2 \text { g) }\end{array}$ & $\begin{array}{c}\text { Group D } \\
\text { (IV } 1 \mathrm{~g}+\text { IA } 4 \text { g) }\end{array}$ & $P$ value \\
\hline Surgical time (minutes) & $89.8 \pm 5.7$ & $88.7 \pm 9.5$ & $87.9 \pm 9.4$ & $90.0 \pm 9.6$ & 0.6043 \\
\hline P.O. 3rd day, Hb (g/L) & $75.9 \pm 3.9^{a, b}$ & $81.7 \pm 3.7^{\mathrm{a}, \mathrm{b}}$ & $93.6 \pm 5.0^{\mathrm{a}}$ & $94.7 \pm 3.6^{b}$ & $<0.0001$ \\
\hline P.O. 7th day, $\mathrm{Hb}(\mathrm{g} / \mathrm{L})$ & $88.4 \pm 2.5^{\mathrm{c}, \mathrm{d}}$ & $91.3 \pm 5.3^{\mathrm{c}, \mathrm{d}}$ & $103.1 \pm 4.5^{c}$ & $103.7 \pm 4.8^{\mathrm{d}}$ & $<0.0001$ \\
\hline 48-h drainage $(\mathrm{mL})^{\ddagger}$ & $529.0 \pm 71.2^{\mathrm{g}, \mathrm{h}}$ & $478.5 \pm 76.2^{\mathrm{g}, \mathrm{h}}$ & $338.4 \pm 47.7^{g}$ & $341.2 \pm 68.1^{\mathrm{h}}$ & $<0.0001$ \\
\hline Patients transfused & 0 & 0 & 0 & 0 & - \\
\hline Transfusion units $(U)$ & 0 & 0 & 0 & 0 & - \\
\hline
\end{tabular}

In the table, matched letters superscript indicated significant differences between matched groups $(P<0.05)$. If the superscripts above any two value are the same or containing one same letter, it means that there is statistical difference between these two groups. If the superscripts on any two value have no matched letter, which means there is no statistical difference for comparison between these two groups. *, means significant differences among four groups; ${ }^{\ddagger}$, comparison of 48-hour drainage between 2 of 4 groups was shown in Table 3. Hb, hemoglobin; P.O., postoperative; DVT, deep vein thrombosis; PE, pulmonary embolism.

migration or nonnative identity.

No significant between-group differences were observed for any demographic, clinical, or outcome variable, and baseline characteristics were comparable among the groups (Table 1). Females accounted for $59.4 \%$ of all the study participants. The mean patient age was $70.9 \pm 5.8$ years (range, 62 to 81 years), and the mean BMI was $24.0 \pm 2.8 \mathrm{~kg} / \mathrm{m}^{2}$. The mean preoperative $\mathrm{Hb}$ level was $127.4 \pm 6.0 \mathrm{~g} / \mathrm{L}$, and the mean surgical time was $89.1 \pm 8.8$ minutes. There was no difference in the severity of osteoarthritis among the 
Table 3 One-way ANOVA comparison of 48-hour drainage between 2 of 4 groups $^{\dagger}$

\begin{tabular}{lcccc}
\hline P value & Group A (IV 1 g + IA 0 g) & Group B (IV 1 g + IA 1 g) & Group C (IV 1 g + IA 2 g) & Group D (IV 1 g + IA 4 g) \\
\hline Group A (IV 1 g + IA 0 g) & - & 0.0043 & $<0.0001$ & $<0.0001$ \\
Group B (IV 1 g + IA 1 g) & 0.0043 & - & $<0.0001$ & $<0.0001$ \\
Group C (IV 1 g + IA 2 g) & $<0.0001$ & $<0.0001$ & - & 0.9975 \\
Group D (IV 1 g + IA 4 g) & $<0.0001$ & $<0.0001$ & 0.9975 & - \\
\hline
\end{tabular}

${ }^{\dagger}$, one-way ANOVA: one-way analysis of variance. The $\mathrm{P}$ value represents the result for comparison of mean values between 2 of the 4 groups in 48-h wound drainage $(\mathrm{P}<0.05$ was considered statistically significant).

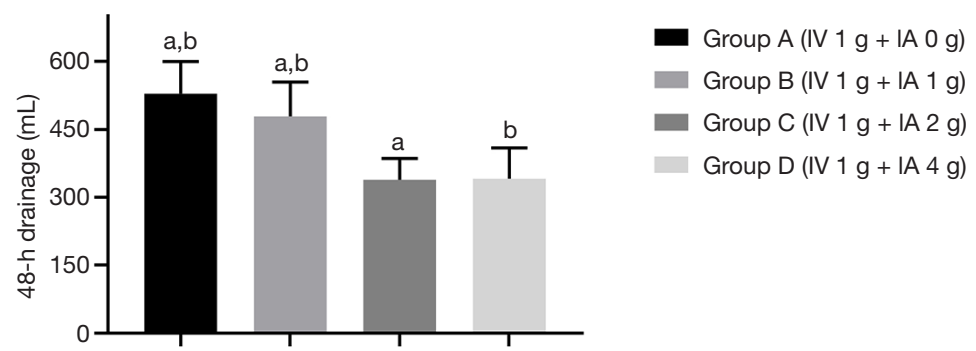

Figure 2 48-hour blood drainage after surgery of 4 groups. Both groups C and D had significant lower outer wound drainage than that in groups $\mathrm{A}$ and $\mathrm{B}(\mathrm{P}<0.05$ was considered statistically significant), while no difference was observed between groups $\mathrm{C}$ and $\mathrm{D}$. [Matched letters superscript indicated significant differences between matched groups $(\mathrm{P}<0.05$ was considered statistically significant). If the superscripts above any two columns are the same or containing one matched letter, which means that there is statistical difference between these two groups. If the superscripts above any two columns have no matched letter, which means there is no statistical difference between these two groups).

groups.

As summarized in Table 2, the mean postoperative

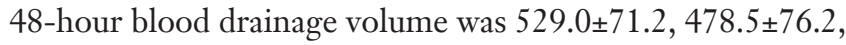
$338.4 \pm 47.7$ and $341.2 \pm 68.1 \mathrm{~mL}$ for groups A, B, C, and D, respectively. Without considering hidden blood loss, groups $\mathrm{C}$ and $\mathrm{D}$ had lower outer wound drainage than groups A and B. Compared with group A, groups C and D had lower mean drainage volumes of $190.6 \mathrm{~mL}$ (95\% CI, 152.1 to $229.1 \mathrm{~mL}, \mathrm{P}<0.0001)$ and $187.8 \mathrm{~mL}$ (95\% CI, 149.5 to $226.1 \mathrm{~mL}, \mathrm{P}<0.0001)$, respectively; compared with group $\mathrm{B}$, groups $\mathrm{C}$ and $\mathrm{D}$ had lower mean drainage volume of $140.1 \mathrm{~mL}$ (95\% CI, 102.1 to $178.1 \mathrm{~mL}, \mathrm{P}<0.0001)$ and $137.3 \mathrm{~mL}$ (95\% CI, 99.50 to $175.1 \mathrm{~mL}, \mathrm{P}<0.0001$ ), respectively. Moreover, a significantly lower drainage volume was observed in group B than in group A $(50.5 \mathrm{~mL}$, $95 \% \mathrm{CI}, 12.23$ to $88.77 \mathrm{~mL}, \mathrm{P}=0.0043)$. For groups $\mathrm{C}$ and $\mathrm{D}$, no difference was observed $(\mathrm{P}=0.9975)$ (Table 3, Figure 2). The $\mathrm{Hb}$ levels in groups $\mathrm{C}$ and group $\mathrm{D}$ were significantly higher than those in group A and B on days 1, 3, and 7 after surgery. However, the difference between groups $\mathrm{C}$ and
D was statistically significant only on day 1 after surgery $(\mathrm{P}<0.0001)$. The $\mathrm{Hb}$ levels in group $\mathrm{A}$ were significantly lower than those in groups $\mathrm{C}$ and $\mathrm{D}$ at 1 month after surgery ( $\mathrm{P}=0.0047$ and $\mathrm{P}=0.0343$, respectively), while only minor intergroup differences were recorded among the other groups (Table 2, Figure 3).

The calculated total blood loss was $1249.72 \pm 266.38$, $1047.36 \pm 281.74,839.17 \pm 272.08$, and $822.74 \pm 247.55 \mathrm{~mL}$ in groups A, B, C, and D, respectively. With the increase of IA dose, total blood loss showed a decreasing trend. There were significant differences between groups except for group $\mathrm{C}$ and $\mathrm{D}$, which were highly consistent with those on 48-hour drainage (Table 4). No patient in any group received an allogeneic blood transfusion postoperatively. One patient in group $\mathrm{C}$ had skin margin necrosis, and one patient in group D developed incision fat tissue liquefaction, which manifested as delayed wound healing, with continuous yellow exudation containing small lipid droplets and no bacterial or fungal growth in the microbial culture. Secondary debridement and re-suturing were performed on 


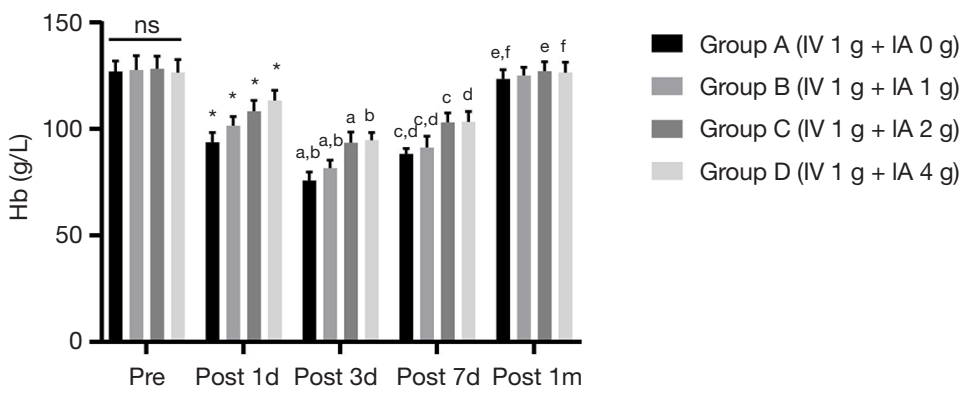

Figure 3 Comparison of $\mathrm{Hb}$ concentration at different time before and after surgery. The Hb level in groups $\mathrm{C}$ and $\mathrm{D}$ was significantly higher than that in groups $\mathrm{A}$ and $\mathrm{B}$ on the 1st, 3rd, and 7th day after surgery. However, the difference between groups $\mathrm{C}$ and $\mathrm{D}$ was statistically significant only on the 1 st day $(\mathrm{P}<0.05$ was considered statistically significant). Hb level in group A were statistically lower than those in groups $\mathrm{C}$ and D at 1 month after surgery, while only minor inter-group difference was recorded among other groups. [Matched letters superscript indicated significant differences between matched groups $(\mathrm{P}<0.05$ was considered statistically significant). If the superscripts above any two columns are the same or containing one matched letter, which means that there is statistical difference between these two groups. If the superscripts above any two columns have no matched letter, which means there is no statistical difference between these two groups. * means significant differences among four groups].

Table 4 One-way ANOVA comparison of calculated total blood loss between 2 of 4 groups $^{\dagger}$

\begin{tabular}{lcccc}
\hline P value & Group A (IV 1 g + IA 0 g) & Group B (IV 1 g + IA 1 g) & Group C (IV 1 g + IA 2 g) & Group D (IV 1 g + IA 4 g) \\
\hline Group A (IV 1 g + IA 0 g) & - & 0.0034 & $<0.0001$ & $<.0001$ \\
Group B (IV 1 g + IA 1 g) & 0.0034 & - & - & 0.0028 \\
Group C (IV 1 g + IA 2 g) & $<0.0001$ & 0.0028 & - & 0.9923 \\
Group D (IV 1 g + IA 4 g) & $<0.0001$ & 0.0010 & 0.9923 & -
\end{tabular}

${ }^{\dagger}$, one-way ANOVA: one-way analysis of variance. The $\mathrm{P}$ value represents the result for comparison of calculated total blood loss between 2 of 4 groups $(P<0.05$ was considered statistically significant).

days 10 and 15 after surgery, respectively. The remaining patients were discharged from the hospital within 1 week after surgery.

At the follow-up 3 months after surgery, the KS-C scores were $90.0 \pm 6.6,89.1 \pm 3.9,90.9 \pm 5.6$, and $88.9 \pm 7.9$ in groups $\mathrm{A}, \mathrm{B}, \mathrm{C}$, and $\mathrm{D}$, respectively. The KS-F scores was $86.4 \pm 3.6$, $85.6 \pm 8.1,87.1 \pm 7.3$ and $86.8 \pm 6.0$ in group $\mathrm{A}, \mathrm{B}, \mathrm{C}$, and D, respectively. There was no statistically significant difference among the four groups, regarding KS-C $(\mathrm{P}=0.4351)$ or KS-F ( $\mathrm{P}=0.7412)$. No episodes of DVT occurred in any patient, and no symptomatic $\mathrm{PE}$ was reported in any of the four groups.

\section{Discussion}

The current well-accepted theory states that hyperfibrinolysis after TKA is an important factor causing massive blood loss. Based on this theory, the use of the antifibrinolytic agent TXA during the perioperative period of TKA can theoretically reduce postoperative blood loos and the need for blood transfusions (15). TXA, a synthetic derivative of lysine, can competitively inhibit plasminogen activation and the combination of fibrin and plasmin and stabilize blood clots and decrease the fibrinolytic process, playing a key role in reducing bleeding $(16,17)$.

It has been reported that TXA has a satisfactory effect of reducing postoperative blood loss without serious thrombotic events. Blood loss can decrease by 250-350 mL, as does the blood transfusion rate (4). Some studies have also shown that the effect of reducing perioperative bleeding was even superior to that of a tourniquet (18). To date, most studies have focused on different ways and frequencies of drug administration. However, no consensus on the ideal dose of combination administration has been reached, especially for IA injection.

In our previous study (9), we directly compared three 
combination regimens and found that topical TXA injection of $2 \mathrm{~g}$ was better than that of $1 \mathrm{~g}$ and comparable to that of $3 \mathrm{~g}$. Whether $2 \mathrm{~g}$ of TXA had reached the "ceiling effect" or because the administration gradient in the experimental group was insufficient, we could not make any conclusions. To address this issue, this study was designed to compare the efficacy of different IA doses of TXA combined with the same single-dose IV injection in reducing blood loss and the risk for thromboembolism and to determine the ideal topical administration dose that is more effective yet without increasing the incidence of thromboembolic complications. Most researchers selected a single $10-20 \mathrm{mg} / \mathrm{kg}$ or $1 \mathrm{~g}$ dose of TXA for IV use before surgery (4,6-8,19-21). Referring to these previous results and calculating according to the instruction manual for intravenous administration of TXA, $1 \mathrm{~g}$ TXA was injected intravenously based on the patients' average weight in the pilot study.

Our primary outcomes were the amount of 48-hour blood drainage from the tube, $\mathrm{Hb}$ concentration, and units of blood transfusion. On average, we found approximately 150 to $200 \mathrm{~mL}$ ( 137.3 to $190.6 \mathrm{~mL}$ ) less blood drainage in the patients of groups C and D compared to those of groups A and B. This equates roughly to 1 unit of allogenic red blood cell suspension. Similarly, these two groups had a significantly smaller decrease in $\mathrm{Hb}$ in the first postoperative week compared to groups A and B. Compared to the placebo group, the $\mathrm{Hb}$ difference still statistically existed 1 month postoperatively. Interestingly, a doseresponse relationship was not identified between groups $\mathrm{C}$ and D. It can be concluded that the effect of reducing blood loss increased with increasing topical dose of TXA. The hemostatic effect of the IA injection of $2 \mathrm{~g}$ TXA was no worse than that of $4 \mathrm{~g}$ TXA, both of which were better than the topical injection of $1 \mathrm{~g}$ TXA or placebo.

The venous thromboembolism (VTE) chemoprophylactic agent of choice in the present study was low-molecular-weight heparin at 4,000 IU per day, which, in conjunction with mechanical devices and early mobilization, is an appropriate form of VTE prophylaxis. No VTE complications were observed before or after discharge from the hospital. Several studies have shown that TXA was quite safe and seldomly associated with thrombotic complications, even in some high risk patients with a history of thromboembolism or being taking anticoagulants (22-24), while Emara et al. (25) observed an increased incidence of thromboembolism events after the IV use of TXA during semi-arthroplasty. The low VTE incidence might be attributed to the fact that TXA is activated and mainly functioned locally at the surgical site. To our knowledge, there is no evidence that the topical injection of TXA into the articular cavity is responsible for postoperative systemic hypercoagulation. However, we must still emphasize that patients will be in a state of hypercoagulation for a considerable period of time after surgery (26) and that prolonged anticoagulant therapy and domestic rehabilitation are strongly recommended.

Except for one patient with skin margin necrosis in group $\mathrm{C}$ and one patient with fat tissue liquefaction in group D, no severe incisional complications were recorded. These two patients achieved secondary healing after debridement and re-suturing. To the best of our knowledge, there is no firm evidence to indicate that skin incision necrosis or fat tissue liquefaction is related to TXA. Yuan et al. (27) noted that a high concentration of TXA injected into the joint cavity may over-activate anti-fibrinolysis and that excessive blood clot formation may block the drainage tube, resulting in local hematoma, joint swelling, and wound dehiscence. Although few side effects or complications related to topical use have been reported, poor healing of the incision will lead to prolonged hospital stays, which will inevitably increase medical costs and the risk of nosocomial joint infection, which is disastrous for joint replacement. We believe that it is necessary for clinicians to pay attention to this potential risk, especially in China, which has an extremely discordant doctor-patient relationship (28). As such, poor results might further aggravate this tense relationship.

In brief, from the perspective of pharmacokinetics, combined with the same single-dose of IV injection, the hemostatic effect of the topical injection of $2 \mathrm{~g}$ TXA was better than that of $1 \mathrm{~g}$ TXA or placebo and comparable to that of $4 \mathrm{~g}$ TXA. Regarding to the relationship between coagulation and anticoagulation in most orthopedic surgeries, TXA itself is a double-edged sword. Theoretically, the lower the topical concentration of TXA is, the lower the risk of thromboembolic side-effects. Regardless of whether TXA is used systemically or topically, it is worthwhile to be vigilant that a low-dose regimen is always preferable in cases in which the effect of TXA is the same.

Several limitations of this study should be mentioned. (I) We mainly collected and analyzed postoperative blood loss through the drainage tube and just calculated total blood loss based on formula. Thus, the actual total blood loss was imprecise and may be underestimated. (II) The dose and frequency of the IV administration of TXA are still controversial. In this study, we administered only a single IV 
dose of TXA before surgery based on previously reported RCTs. Further studies should be carried out to verify whether this is the best regimen and the frequencies of IV injection. (III) The clamping time of the drainage tube after surgery is rarely reported in the existing literature, and it was set at 1 hour based on a few clinical studies. Whether 1 hour is an optimal time needs further study. (IV) Doppler ultrasonography instead of venography was used to rule out DVT. PE was excluded through clinical observation rather than CTA. Therefore, diagnoses may have been missed in some patients with mild signs. (V) Because of the number of patients, this study was underpowered to draw any meaningful conclusion with regard to safety. Multicenter prospective studies with a larger number of patients can help address these issues and verify the conclusion of the present study.

\section{Conclusions}

In conclusion, the combined use strategy of TXA in TKA can more effectively reduce blood loss after surgery than a single IV injection of TXA and may not increase the risk of thromboembolic disease. The topical injection of $2 \mathrm{~g}$ TXA may have reached the "ceiling effect" of local use. The preoperative IV injection of $1 \mathrm{~g}$ TXA combined with the IA topical injection of $2 \mathrm{~g}$ TXA after wound closure can effectively reduce postoperative blood loss, making it an optimal combination drug regimen.

\section{Acknowledgments}

Funding: None.

\section{Footnote}

Reporting Checklist: The authors have completed the CONSORT reporting checklist. Available at http://dx.doi. org/10.21037/atm-20-3064

Data Sharing Statement: Available at http://dx.doi. org/10.21037/atm-20-3064

Conflicts of Interest: All authors have completed the ICMJE uniform disclosure form (available at http://dx.doi. org/10.21037/atm-20-3064). The authors have no conflicts of interest to declare.

Ethical Statement: The authors are accountable for all aspects of the work in ensuring that questions related to the accuracy or integrity of any part of the work are appropriately investigated and resolved. The study was conducted in accordance with the Declaration of Helsinki (as revised in 2013). Ethics approval was obtained from the Ethics Committee of Nantong Sixth People's Hospital (Approval No. 201704), and written informed consent was obtained from all participants.

Open Access Statement: This is an Open Access article distributed in accordance with the Creative Commons Attribution-NonCommercial-NoDerivs 4.0 International License (CC BY-NC-ND 4.0), which permits the noncommercial replication and distribution of the article with the strict proviso that no changes or edits are made and the original work is properly cited (including links to both the formal publication through the relevant DOI and the license). See: https://creativecommons.org/licenses/by-nc-nd/4.0/.

\section{References}

1. Kurtz SM, Ong K, Lau E, et al. Impact of the economic downturn on total joint replacement demand in the United States: updated projections to 2021. J Bone Joint Surg Am 2014;96:624-30.

2. Yanik JM, Bedard NA, Hanley JM, et al. Rapid Recovery Total Joint Arthroplasty is Safe, Efficient, and CostEffective in the Veterans Administration Setting. J Arthroplasty 2018;33:3138-42.

3. To J, Sinha R, Kim SW, et al. Predicting Perioperative Transfusion in Elective Hip and Knee Arthroplasty: A Validated Predictive Model. Anesthesiology 2017;127:317-25.

4. Stowers MD, Aoina J, Vane A, et al. Tranexamic Acid in Knee Surgery Study-A Multicentered, Randomized, Controlled Trial. J Arthroplasty 2017;32:3379-84.

5. Liu X, Liu J, Sun G. A comparison of combined intravenous and topical administration of tranexamic acid with intravenous tranexamic acid alone for blood loss reduction after total hip arthroplasty: A meta-analysis. Int J Surg 2017;41:34-43.

6. Yuan X, Wang J, Wang Q, et al. Synergistic effects of intravenous and intra-articular tranexamic acid on reducing hemoglobin loss in revision total knee arthroplasty: a prospective, randomized, controlled study. Transfusion 2018;58:982-8.

7. Nielsen CS, Jans Ø, Ørsnes T, et al. Combined IntraArticular and Intravenous Tranexamic Acid Reduces Blood 
Loss in Total Knee Arthroplasty: A Randomized, DoubleBlind, Placebo-Controlled Trial. J Bone Joint Surg Am 2016;98:835-41.

8. Peng Zhang MM, Jifeng Li MM, Xiao Wang MM. Combined versus single application of tranexamic acid in total knee and hip arthroplasty: A meta-analysis of randomized controlled trials. Int J Surg 2017;43:171-80.

9. Wu J, Li G, Chen Y, et al. Comparison of combined intravenous and topical use of tranexamic acid with different dosage in primary total knee arthroplasty. Zhongguo Xiu Fu Chong Jian Wai Ke Za Zhi 2018;32:1397-401.

10. Zongke Z, Xisheng W, Tiebing Q, et al. Expert consensus in enhanced recovery after total hip and knee arthroplasty in China: perioperative management. Chinese Journal of Bone and Joint Surgery 2016;9:1-9.

11. Mont MA, Jacobs JJ. AAOS clinical practice guideline: preventing venous thromboembolic disease in patients undergoing elective hip and knee arthroplasty. J Am Acad Orthop Surg 2011;19:777-8.

12. Bala A, Huddleston JI 3rd, Goodman SB, et al. Venous Thromboembolism Prophylaxis After TKA: Aspirin, Warfarin, Enoxaparin, or Factor Xa Inhibitors? Clin Orthop Relat Res 2017;475:2205-13.

13. Good L, Peterson E, Lisander B. Tranexamic acid decreases external blood loss but not hidden blood loss in total knee replacement. Br J Anaesth 2003;90:596-9.

14. Nadler SB, Hidalgo JH, Bloch T. Prediction of blood volume in normal human adults. Surgery 1962;51:224-32.

15. Lei Y, Xie J, Xu B, et al. The efficacy and safety of multiple-dose intravenous tranexamic acid on blood loss following total knee arthroplasty: a randomized controlled trial. Int Orthop 2017;41:2053-9.

16. Cole E, Davenport R, Willett K, et al. Tranexamic acid use in severely injured civilian patients and the effects on outcomes: a prospective cohort study. Ann Surg 2015;261:390-4.

17. Cao G, Huang Q, Huang $Z$, et al. The efficacy and safety of multiple-dose oral tranexamic acid on blood loss following total hip arthroplasty: a randomized controlled trial. Int Orthop 2019;43:299-305.

18. Huang Z, Xie X, Li L, et al. Intravenous and Topical Tranexamic Acid Alone Are Superior to Tourniquet Use for Primary Total Knee Arthroplasty: A Prospective, Randomized Controlled Trial. J Bone Joint Surg Am 2017;99:2053-61.

19. Lee SY, Chong S, Balasubramanian D, et al. What is the
Ideal Route of Administration of Tranexamic Acid in TKA? A Randomized Controlled Trial. Clin Orthop Relat Res 2017;475:1987-96.

20. Subramanyam KN, Khanchandani P, Tulajaprasad P, et al. Efficacy and safety of intra-articular versus intravenous tranexamic acid in reducing perioperative blood loss in total knee arthroplasty: a prospective randomized doubleblind equivalence trial. Bone Joint J 2018;100-B:152-60.

21. Boese CK, Centeno L, Walters R. Blood Conservation Using Tranexamic Acid Is Not Superior to EpsilonAminocaproic Acid After Total Knee Arthroplasty. J Bone Joint Surg Am 2017;99:1621-8.

22. Heller S, Secrist E, Shahi A, et al. Tranexamic Acid Can Be Administered to Arthroplasty Patients Who Receive Aspirin for Venous Thromboembolic Prophylaxis. J Arthroplasty 2016;31:1437-41.

23. Kim YT, Kang M, Lee J, et al. Combined use of topical intraarticular tranexamic acid and rivaroxaban in total knee arthroplasty safely reduces blood loss, transfusion rates, and wound complications without increasing the risk of thrombosis. BMC Musculoskelet Disord 2018;19:227.

24. Yates J, Perelman I, Khair S, et al. Exclusion criteria and adverse events in perioperative trials of tranexamic acid: a systematic review and meta-analysis. Transfusion 2019;59:806-24.

25. Emara WM, Moez K, Elkhouly A. Topical versus intravenous tranexamic acid as a blood conservation intervention for reduction of post-operative bleeding in hemiarthroplasty. Anesth Essays Res 2014;8:48-53.

26. Yi Z, Bin S, Jing Y, et al. Tranexamic Acid Administration in Primary Total Hip Arthroplasty: A Randomized Controlled Trial of Intravenous Combined with Topical Versus Single-Dose Intravenous Administration. J Bone Joint Surg Am 2016;98:983-91.

27. Yuan X, Li B, Wang Q, et al. Comparison of 3 Routes of Administration of Tranexamic Acid on Primary Unilateral Total Knee Arthroplasty: A Prospective, Randomized, Controlled Study. J Arthroplasty 2017;32:2738-43.

28. $\mathrm{Xu} \mathrm{W}$. Violence against doctors in China. Lancet 2014;384:745.

Cite this article as: $\mathrm{Wu} \mathrm{J}$, Zhou YQ, Deng JH, Han YG, Zhu YC, Qian QR. Ideal intraarticular application dose of tranexamic acid in primary total knee arthroplasty: a prospective, randomized and controlled study. Ann Transl Med 2020;8(21):1353. doi: 10.21037/atm-20-3064 